\title{
An Empirical Study Of Student Attitudes Toward Acceptance Of Online Instruction And Distance Learning
}

Dat-Dao Nguyen, California State University - Northridge, USA

Yue "Jeff" Zhang, California State University - Northridge, USA

\begin{abstract}
This study investigates to what extent student attitudes toward acceptance of online instruction and Distance Learning are affected by determinants such as demographics, learning environment, learning domains, delivery methods, and web-based instructional technology. Logistic Regression and Discriminant Analysis use statistically significant determinants to predict student preference on future online classes. Factor Analysis provides an exploratory model of online learning acceptance having three factors; namely, Communication/Feedback, Course Outcome, and Effort Required. Practical implications of findings and insights on field observations are offered. Overall, students agreed that they had learned sufficient knowledge from an online course. Students satisfied with their recent learning outcome tend to take more online courses in the future.
\end{abstract}

Keywords: Distance Learning; Instructional Design; Online Instruction; Web-based Instructional Technology

\section{INTRODUCTION}

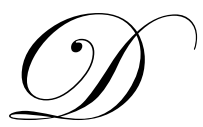

istance Learning and Virtual Classroom (Hiltz, 1994; Hiltz \& Wellman, 1997; and Hiltz \& Arbaugh, 2003) have provided opportunities for students to overcome individual restrictions/difficulties in order to access the instructions at their convenience at any time and any place. With the proliferation of information technology at a low cost and with the ease to access the World Wide Web, online instruction over the Internet has become a supplement and/or replacement of traditional classes (Allen \& Seaman, 2006, and Arbaugh et al., 2009).

From a learning theory and instructional design perspective (Gagne \& Briggs, 1974; Gagne, 1985; and Worthen \& Sanders, 1987), an instructional design should be evaluated during the course to monitor the ongoing delivery and learning process, or at the end of the course to assess the effectiveness of teaching and learning, taking into consideration student characteristics, subject matter, instructional methods and media. Research indicates that traditional learning practices in classrooms may not be suitable for the online environment due to differences in the storage, delivery and presentation of knowledge (Rungtusanatham et al., 2004; Yan, 2004). Several frameworks and conceptual models for effective online learning have been proposed (Wang, 2003; Marks et al., 2005; Moore, 2005; Holsapple \& Lee-Post, 2006; and Eom et al., 2006).

This study investigates to what extent student attitudes toward acceptance of online instruction and Distance Learning are affected by determinants such as demographics, learning environment, learning domains, delivery methods, and web-based instructional technology. It addresses the following questions: 1) What learning characteristics make a difference in the performance of online students and 2) What factors in the student learning process and outcome make a difference in their attitudes toward the reuse intention and acceptance of future online courses. Statistical tools, such as logistic regression, discriminant analysis, and factor analysis, are applied to obtain practical comprehensive and predictive models of student attitudes toward acceptance of online instruction. Significant student characteristics of learning, performance indicators, and their effects in quantitative models, once 
defined, would contribute to the improvement of instructional design in order to gain student acceptance of online courses and provide them with positive and productive learning experiences.

\section{A FRAMEWORK FOR EVALUATION}

Meta-analyses (Arbaugh et al, 2009, and Zawacki-Richter et al, 2009) identified three primary themes in research of Distance Learning - narrative accounts of instructors' experiences and their best practices; empirical studies of student perceptions, attitudes, and behaviors toward online courses; and comparative studies of online versus traditional classes. Researchers are dominated by issues related to instructional design and individual learning processes. From an instructor's perspective, literature has reported on effects of using specific web-based media/technologies to deliver specific types of instructional material over the Internet (Holsapple \& Lee-Post, 2006). From a student's perspective, studies have focused on how demographics and perceptions affecting the acceptance of web-based instructional technology (Lu et al., 2003; Schniederjans \& Kim, 2005; Eom et al., 2006; Wan, Wang \& Haggerty, 2008; and Harrington \& Loffredo, 2010). Given these two perspectives, the issue is how to deliver effectively the course contents in an online class to meet student preferences and aptitudes. Ideally, students should take an online class by their own preference rather than by it being the only choice of available courses in an online format.

Previous studies have identified various determinants of learner satisfaction and effective online learning. Wang (2003), based on 17 indicators to propose an exploratory model of four factors (Learner Interface, Learning Community, Content, and Personalization) affecting e-learner satisfaction. Marks et al. (2005) analyzed 67 indicators of course interaction, perceived learning/course quality, instructor behaviors, advantages/flexibility, and course satisfaction to present a Structural Equation Model of five factors (Instructor-student, Student-student, Online advantages, Group projects, Individual projects) for Perceived Learning, and ultimately Satisfaction. Eom et al. (2006) used 22 indicators to indentify six factors (Student Self-motivation, Student Learning Style, Instructor Knowledge and Facilitation, Instructor Feedback, Interaction, Course Structure) affecting two latent variables Perceived Student Satisfaction and Learning Outcomes.

Alternatively, this study proposes comprehensive models for understanding and predicting student acceptance of online instruction from a Learning Theory and Instructional Design perspective (Gagne \& Briggs, 1974; Gagne, 1985; and Worthen \& Sanders, 1987). First, it investigates whether there is any significant effect of individual and environmental characteristics on learning. Then, student attitudes toward the learning process and outcome are analyzed to predict what makes them take another online class. It proposes an exploratory model toward acceptance of online instruction and Distance Learning. At the end, it documents some field observations and insights from the instructor/co-researcher who taught the course.

In the following, selected determinants identified in the literature are discussed for an evaluation instrument. Characteristics of learning - independent variables - such as student demographics, learning environment, learning domain, and delivery methods, are reviewed. Then performance indicators - dependent variables - are defined for a framework of acceptance of online instruction.

\section{Characteristics Of Learning}

\section{Student Demographics}

In traditional Learning Theory, age and gender are considered two natural traits that may affect learning and persistence (Gagne, 1985). It has been found that attitudes toward willingness to learn independently, selfregulation versus hands-on and/or close supervision may be different across demographic groups to make Distance Learning a successful experience (Hiltz, 1994). Work experience and level of education - representing a level of maturity - may contribute as motivators for learning (Leidner \& Jarvenpaa, 1995).

Almost all researches address issues related to student demographics (for instance, Arbaugh, 2000; Lu et al, 2003; Wang, 2003; and Marks et al., 2005). However, clear effects of student demographics in their online learning have not been strongly supported. Nevertheless, literature indicates that mature and full-time students did better in 
online classes due to their motivation and preparedness ( $\mathrm{Lu}$ et al, 2003). In terms of gender, female students have a stronger pragmatic perspective in learning, contribute less in posting messages, but ask more questions/clarifications and participate more in online discussion. In contrast, male students prefer more complex issues, spend more time with learning modules, are comfortable with web-based technologies, but are less persistent in learning (Astleitner \& Steinberg, 2005).

Following the tradition, this study takes student demographics into consideration to better understand the composition of the sample. Further, it attempts to discover any significant differences in attitudes toward the learning process and outcomes across student groups in this context.

\section{Learning Environment}

From a Learning Theory and Instructional Design perspective, a learning environment could be characterized by synchronous versus asynchronous learning, the degree of interaction between learner-learners, learner-teacher, learner-content, and learner-instructional media (Hiltz, 1994, and Marks et al., 2005).

Synchronous learning, as in a traditional class, has a disadvantage in its limited access to time and place - a fixed schedule in a specific classroom. Its merit is in the immediate face-to-face interactions between learner and other learners, teacher, and content that are supposed to motivate an interest in learning and to reinforce knowledge acquisition process. The physical proximity may create a sense of belonging and an exchange of emotional support (Hiltz \& Wellman, 1997). However, the social atmosphere of a classroom may nurture a tendency of group conformity to the opinion expressed by the instructor and/or the peers. Then, a student with individual creativity/initiative may have to slow down his/her progress to the pace of the class.

Asynchronous learning, specifically in an online class, has a prominent advantage in offering unlimited access to class contents/materials at any time and any place. A flexible schedule of course delivery allows a student to progress at his/her own pace. The most commonly cited drawback lies in the asynchronous communication with instructor and peers as students may not get instant answers to their questions on a certain topic. They do not get immediate feedback on their response/reaction to class materials and instructional delivery in order to reinforce their learning (Gagne, 1985). However, with recent development of Internet-based communication technologies, one could have real-time online feedback with instructors and peers and even create a virtual learning community (Karacapilidis, 2010).

This study looks into the merit of asynchronous learning, not only to confirm the advantage of an important factor in Distance Learning, but also to explore whether this benefit has gained a wide acceptance from students, as well as how to address the issue in a course design and delivery process.

\section{Learning Domains}

A learning domain represents the type of knowledge to be delivered in the course (Schrag, 1992). In some cases, a learning domain may define specific delivery methods for instructional design. For instance, a concrete hands-on knowledge may be more difficult to be delivered online without using audio-visual media and instant feedback. In the beginning, it was uncertain on which subject matter and content type are best suited to deliver in Distance Learning (Piccoli et al., 2001). However, a recent meta-analysis reports that online and hybrid learning has been implemented in almost all business disciplines (Arbaugh et al, 2009). A cross-disciplinary study by Hornik et al (2008), based on data from 13,000 students in 167 online courses between 1997 and 2003, found that student grades were higher and withdrawals were lower for subjects with "high paradigm" development (hard sciences having general agreement on key definitions and acceptable methodologies) than those with "low paradigm" development (social sciences, humanities, etc.)

A comprehensive study on instructional design of online courses should discover what type of knowledge would be expected by learners. Then one should find out whether the current state of web-based technology could alternatively support the delivery of subject matters/contents that have been covered in traditional classes. 


\section{Delivery Methods}

Delivery methods relate to elements of instructional design, such as interactive/passive mode, learning aids/tools, and performance evaluation (Gagne \& Briggs, 1974). They address issues whether an instructor should transfer a body of knowledge through lecture or invite a participation/dialogue from students, what instructional media to use for delivery, and what instruments to evaluate students' performance.

Research has reported on using a variety of web-based media (e-mail, posting, video conference, chat room, blogs ...) to deliver specific type of instructional materials (class notes, lectures, discussions, group projects, individual assignments, tests ...) over the Internet (Janicki \& Steinberg, 2003; Holsapple \& Lee-Post, 2006; and Karacapilidis, 2010).

This study investigates student preferences toward available web-based technologies used in the sample, such as posted course materials (annotated screenshots/animation/written description lectures notes, and audio/video clips), calendar, chat room, message board, online assignments and quizzes. It focuses on student attitudes toward various functionalities of web-based Distance Learning technologies instead of on the interfaces of a specific tool in a learning management system (LMS). Preference of a specific delivery method - for instance, how often students accessing a variety of functions of a online course - could reveal the patterns of learning and contribute to the effective implementation of an instructional media to assist students in their learning.

\section{Performance Indicators}

Characteristics of learning discussed above are expected to have influences on effective learning in terms of increase in knowledge, application of new knowledge, and positive reactions to the course delivery (Lengnick-Hall \& Sanders, 1997, and Moore J.C., 2005). Consequently, an instructional evaluation should discover which factors have significant effects on the outcome of learning and the response to learning process to assess the effectiveness of student learning and instructional design. One should evaluate how much students have learned from the course, how they feel about the sufficiency of acquired knowledge, the degree of satisfaction with the instruction, and the intention to recommend the course to others (Merrill, 1994, and Moore, 2005). Students, who are satisfied users having positive attitudes toward their performance in the class, are expected to have a high level of reuse intention for the learning system (Melone, 1990, and Marks et al., 2005). A positive learning experience from an online course might create favorable preference for this type of instructional design and might lead to the acceptance/reuse intention of other online courses in the future.

\section{Response To Learning Process}

Attitudes toward delivery process could be represented by perceived easiness/difficulties in using various instructional technology/media in an online class. For a student, ease of learning may include comprehensive presentation of course content, feedback from instructor, and communication with classmates (Hiltz, 1994). The course content should be appropriate for an average participant in the target audience. Timely feedback from the instructor should be available to refine knowledge by focusing on relevant information. Frequent interaction with instructor and classmates is necessary to reinforce the acquired knowledge, enhance learning interest, and broaden the student's view on the subject matter (Gagne, 1985).

In light of related previous works (Arbaugh et al, 2009; Zawacki-Richter et al, 2009; and Ritzhaupt et al., 2010), this study investigates whether students have benefitted from a flexible schedule of an online class, how much time and effort have been spent to keep up with material and assignment, and the possible influence of missing prominent aspects of traditional classroom, such as face-to-face communication, instant response with classmates, and instructor.

\section{Outcome Of Learning}

After successfully completing a course, a learner is expected to acquire improvements in personal beliefs, actions, skills, and abilities (Lengnick-Hall \& Sanders, 1997). One could measure the mastering of intended contents 
and learning goals by the degree of completion of course requirements. Since normative criteria of student performance have been defined, one should be able to assess how well students have learned from a course through their class work. In addition, one could measure the relative achievement in comparison with other group of learners, especially those in online classes versus those in traditional classes. Attitudes toward the learning outcome could be represented by how students value results corresponding to their efforts in time, work and other opportunity costs in order to take the course - a good return on investment (Lengnick-Hall \& Sanders, 1997). The outcome should be worthwhile for students in their intellectual as well as professional development. Students should be able to provide qualitative assessments to express their attitudes toward the usefulness of content and make comparisons across other learning experiences taken inside, as well as outside, the classroom environment (Moore J.C., 2005).

Based on selected indicators in the literature (Arbaugh et al., 2009; Zawacki-Richter et al., 2009; and Ritzhaupt et al., 2010), this study investigates whether 1) leniency of the instructor plays any part in their outcomes, 2) the same content, as in a traditional class, has been delivered, 3) the grades reflect their true performance, and 4) the online course provides sufficient prerequisite knowledge to follow other courses in the curriculum.

In addition to a student survey, this study has access to field observations on student performance and learning behavior in an online class in comparison with those of traditional classes covering the same contents by the same instructor. This provides some insight on the students' actual learning experiences versus expectations and offers some explanations for student attitudes toward their learning outcomes and processes.

\section{EMPIRICAL FINDINGS AND DISCUSSIONS}

Results reported herein are based on responses from a sample of 105 students taking an online introduction course to Information Systems at a major western United States state university. This is a service course for junior students enrolled in the College of Business. The survey was conducted in the beginning of in-class final examination period by the co-researcher, who did not teach the course. It took about ten minutes to complete the questionnaire.

This study addresses the following questions:

- What learning characteristics make a difference in the performance of online students?

- What factors in the student learning process and outcome make a difference in their attitudes toward the reuse intention and acceptance of a future online course?

Ninety-eight variables were collected to gather information on demographics, preferences on learning environment and instructional delivery methods, and attitudes toward learning process and outcome. These variables cover learning characteristics and performance indicators of the evaluation framework discussed in the previous section.

\section{Effects Of Learning Characteristics On Online Student Performance}

\section{Student Demographics}

In this sample, $41 \%$ of respondents were male and 59\% were female. The age distribution was $53.3 \%$ (2024 year old), 30.5\% (25-29 year old), and 16.2\% (30 and older). On the average, respondents worked 25.37 hours per week with 7.5 years in the labor market. The distribution of academic status of these respondents was $80 \%$ fulltime and 20\% part-time students. Over all, respondents had an average of 4.6 years in college. This is a sample of typical college students who study full-time but hold part-time jobs at the same time. They also already took some general education courses before enrolling in the business-oriented courses of their majors.

\section{Reasons For Taking Online Course}

On the reason of taking this online course, $66.7 \%$ of respondents enrolled from a personal preference of flexible schedule for studying, whereas $33.3 \%$ had no choice of a traditional course offered by the college. Of the 
male students in the sample, $72.1 \%$ took the course from a personal choice, whereas $62.9 \%$ of female students did so. Preferences for online course across age groups are 67.9\% (20-24 group), 62.5\% (25-29 group), and 76.9\% (30 and older). In terms of academic status, $69 \%$ of full-time students enrolled in this online course from a personal preference, whereas $57 \%$ of part-time students did so. Apparently, the sample reveals a personal preference from full-time and/or mature students for the online course.

\section{Expected Contents}

Most respondents in this study were full-time students and had been exposed to general education courses in other domains/disciplines. On the contents of the course, $81 \%$ of respondents expected to learn hands-on technical skills, $49.5 \%$ expected to learn general business knowledge, $41 \%$ expected to learn specialized knowledge, $32.2 \%$ expected to learn critical thinking skills, and $20 \%$ expected to learn communication skills. One notes that even in an introductory course of Information Systems, students still expected a variety of contents could be deliverable online. Consequently, the learning domain covered in a distance learning environment could be broad and one should discover appropriate delivery methods to meet the needs of the audience.

\section{Preferences For Delivery Methods}

To deliver course materials, the instructor of this online class used a variety of media in the course webpage as well as other features provided by WebCT, such as posted course materials (annotated screenshots/animation/written description lectures notes, and audio/video clips), calendar, chat room, message board, online assignments and quizzes. In terms of preference for specific instructional delivery methods, $35 \%$ of the respondents liked posted course outline and handouts the most for multiple reasons, such as ease of use $(60 \%)$, providing sufficient material/information (43.8\%), and enhancing student learning (21.9\%). The feature they liked the least is message board $(41 \%)$ for multiple reasons, such as not useful to enhance learning $(30 \%)$ and unattractive design (28.6\%).

In this online class, students communicated with their classmates through multiple media, such as message board $(64.8 \%)$ and e-mail $(63.8 \%)$. In a same manner, they communicated with their instructor through message board $(78.1 \%)$ and email $(70.5 \%)$.

From the expressed preferences, one notes that although students used message board more often in communication, they still disliked this feature. A quick follow-up reveals that students were distracted from and overwhelmed with the volume of information and various threads of discussion on class materials.

In this online class, students received response emails from their instructor in 16 hours, on the average, compared to 26 hours from instructors of traditional classes. Twenty-one percent of students sent their instructor emails for urgent help after hours (late evening and/or early morning) and these urgent e-mails were responded to in 2.3 hours.

The proportions of media used in a group project of this online class were $66.26 \%$ for email, $21.91 \%$ for online chatting, $7.89 \%$ for telephone, and $3.94 \%$ for face-to-face meeting. Respondents also provided the following proportions of using communication media in their group projects for other traditional classes - $26.87 \%$ for email, $20.13 \%$ for online chatting, $13 \%$ for telephone, and $39 \%$ for face-to-face meetings.

One notes that, even while working on group projects in a traditional class, students have a tendency to use more electronic and wireless communication media rather than having face-to-face meetings. This fact may be specific to the sample collected in this study as these students were working and commuted to school, so they could not make to face-to-face meetings for group projects as in other traditional classes.

\section{Attitudes Toward Learning Process And Outcome}

On learning experience, the average expressed attitudes/perceptions for most issues under study are more than neutral/indifferent with a score of higher than 3 on a 5-point Likert scale (from 1 for Strongly Disagree to 5 for 
Strongly Agree). In the following, Table 1 presents indicators of students' perceptions of the learning process (Variables 1 to 11 or V1-V11) and outcome (Variables 12 to 15 or V12-V15). Tables 2 presents differences in perceptions between two groups of students who will or will not take another online course.

Table 1: Indicators Of Perceptions On Learning Process

\begin{tabular}{|c|c|c|}
\hline Variables/Indicators & Mean * & Std. Deviation \\
\hline \multicolumn{3}{|l|}{ Perceptions on Learning Process } \\
\hline V1. Flexible class schedule enhance learning & 3.10 & 1.14 \\
\hline V2. Have more effort to keep up with progress of the class & 3.85 & 1.22 \\
\hline V3. Have more material to learn than traditional class & 3.96 & 1.18 \\
\hline V4. Spend more time to learn materials of online class & 3.92 & 1.20 \\
\hline V5. Spend more time to do assignments than traditional class & 3.70 & 1.16 \\
\hline V6. Feel missing face-to-face communication with instructor and classmates & 3.56 & 1.32 \\
\hline V7. Missing face-to-face communication with instructor and classmates negatively affect study & 3.18 & 1.36 \\
\hline V8. Feel missing the chance to ask instant questions & 3.70 & 1.36 \\
\hline V9. Missing the chance to ask instant questions negatively affect studying & 3.16 & 1.37 \\
\hline V10. Know relative performance in comparison with classmates in online course & 3.18 & 1.19 \\
\hline V11. Knowing relative performance positively affect learning progress & 3.46 & 1.05 \\
\hline \multicolumn{3}{|l|}{ Perceptions on Learning Outcomes } \\
\hline V12. Instructor is more lenient in an online class than in a traditional class & 3.04 & 1.18 \\
\hline V13. Have acquired the same content and skills as in traditional class. & 2.81 & 1.09 \\
\hline V14. Grade from online course reflect accurately true performance & 2.76 & 1.29 \\
\hline $\begin{array}{l}\text { V15. Online course provide sufficient knowledge / skills / prerequisites to follow other courses } \\
\text { in curriculum }\end{array}$ & 3.27 & 1.08 \\
\hline
\end{tabular}

* On a 5-point Likert scale

\section{Perceptions On Learning Process}

Students perceived that a flexible class schedule of an online course enhanced their learning process (V1). However, they felt that they had to put forth more effort to keep up with the progress of the online class (V2). Students felt that they had more materials to learn (V3) and had to spend more time to learn these materials than those of traditional classes (V4, V5).

Students felt they would miss face-to-face communication with the instructor and classmates when taking an online course (V6). The fact of missing face-to-face communication somewhat negatively affected their study (V7). Similarly, students felt they would miss the chance to ask instant questions as in a traditional class (V8). This fact slightly affected their study in a negative way (V9).

Although without face-to-face meetings, students in this online class felt that they did know their relative performance in comparison to their classmates (V10), as the instructor posted class grades with individual codes for students to look up their own grades. This positively affected their learning progress (V11).

\section{Perceptions On Learning Outcome}

On self-evaluations of their performance, online students did not strongly think that they had benefitted from the instructor's leniency more than in a traditional class (V12). They perceived that grades from this online course did not accurately reflect their true performance (V14). They also indicated that they did not learn more knowledge from this online class than from a traditional class (V13). However, students tended to agree that they had learned sufficient knowledge to follow other courses in their curricula (V15).

T-tests have been conducted to discover any significant differences in perceptions between age groups (over vs. under 25 years of age), genders (male vs. female), and academic status (full-time vs. part-time). Overall, the tests show no differences in preferences and perceptions expressed by different genders. However, the following significant differences in perceptions across age groups and academic status have been identified: 
- $\quad$ Adult students, in the age groups of 25 and over, were more concerned about the negative effect of missing face-to-face communication in an online class. Their mean score is 3.41 vs. 2.98 of the younger group. The p-value of this test is 0.10 .

- $\quad$ Adult students, in the age groups of 25 and over, had a stronger belief that knowing relative performance in comparison to their classmates would positively affect their learning progress. Their mean score is $3.39 \mathrm{vs.}$ 3.00 of the younger group. The p-value of this test is 0.10 .

- $\quad$ Full-time students had a stronger belief that knowing relative performance in comparison to their classmates would positively affect their learning progress. Their mean score is 3.55 vs. 3.10 of the parttime group. The p-value of this test is 0.07 .

From the student profile of this sample, although the majority of full-time and adult students took this online course by their own preference, they still expressed their concerns about the lack of face-to-face communication. However, they had stronger beliefs on positive effect of knowing relative performance in class on their learning. In this class, the instructor regularly posted assignment grades with individual codes to inform students on their progress.

\section{Preference For Future Online Course}

There exist statistically significant differences in perceptions on learning outcome between students who will take a future online course (Group 1) and those who will not (Group 2). At a significant level of 0.05, t-tests reported in Table 2 reject the hypotheses of equal mean scores of variables related to perceptions on learning outcome between two groups (all except V10-V11 on knowing relative performance and V12 on instructor's leniency). Results reveal that students who will not take a similar online course in the future are those who have had more negative perceptions regarding the effects of distance learning environment on their learning process and less satisfaction on their recent learning outcomes. In contrast, students who will take a similar online course are those who have had less negative perceptions on their learning process and more satisfaction on their recent learning outcome.

Table 2: Perceptions On Learning By Future Preferences

\begin{tabular}{|c|c|c|c|}
\hline Variables/Indicators & Mean 1* & Mean 2** & $\begin{array}{c}\text { t-test } \\
\text { p-values }\end{array}$ \\
\hline \multicolumn{4}{|l|}{ Perceptions on Learning Process } \\
\hline V1. Flexible class schedule enhance learning & 3.61 & 2.61 & .000 \\
\hline V2. Have more effort to keep up with progress of the class & 3.61 & 4.06 & .067 \\
\hline V3. Have more material to learn than traditional class & 3.59 & 4.30 & .002 \\
\hline V4. Spend more time to learn materials of online class & 3.45 & 4.35 & .000 \\
\hline V5. Spend more time to do assignments than traditional class & 3.27 & 4.07 & .000 \\
\hline V6. Feel missing face-to-face communication with instructor and classmates & 2.86 & 4.20 & .000 \\
\hline $\begin{array}{l}\text { V7. Missing face-to-face communication with instructor and classmates } \\
\text { negatively affect study }\end{array}$ & 2.67 & 3.65 & .000 \\
\hline V8. Feel missing the chance to ask instant questions & 3.31 & 4.06 & .005 \\
\hline V9. Missing the chance to ask instant questions negatively affect studying & 2.78 & 3.52 & .006 \\
\hline V10. Know relative performance in comparison with classmates in online course & 3.31 & 3.07 & .330 \\
\hline V11. Knowing relative performance positively affect learning progress & 3.39 & 3.50 & .589 \\
\hline \multicolumn{4}{|l|}{ Perceptions on Learning Outcome } \\
\hline V12. Instructor is more lenient in an online class than in a traditional class & 3.14 & 2.94 & .400 \\
\hline V13. Have acquired the same content and skills as in traditional class. & 3.16 & 2.44 & .001 \\
\hline V14. Grade from online course reflect accurately true performance & 3.20 & 2.31 & .000 \\
\hline $\begin{array}{l}\text { V15. Online course provide sufficient knowledge / skills / prerequisites to follow } \\
\text { other courses in curriculum }\end{array}$ & 3.69 & 2.87 & .000 \\
\hline
\end{tabular}

* Group 1: Students will take an online course again

** Group 2: Students will not take an online course again 
When respondents were asked whether they would take an online course again, $57.1 \%$ of those who chose the current online course from their own preference would do it, whereas $25.7 \%$ of those who had no choice would do so. There is a weak correlation between expressed initial preference and future preference for a similar online course $(\mathrm{r}=.176$ with $\mathrm{p}$-value $=.07)$. This indicates that preference for a future online course builds up with positive experience on the recent course taken. A recent unsatisfactory experience with an online course may contribute to a negative effect on future choices.

\section{Why A Student Decides To Take A Future Online Class}

A Logistic Regression is conducted to find out which performance indicators would affect the student's decision on taking a future online course. Through stepwise regression, the following coefficients are obtained.

$\mathrm{Z}=5.867+.804 \mathrm{~V} 1-.727 \mathrm{~V} 3-.625 \mathrm{~V} 5-.965 \mathrm{~V} 6$

$\begin{array}{lllll}(1.993) \quad(.296) & (.258) \quad(.261) \quad(.251)\end{array}$

where V1 = Perception on benefit of flexible class schedule

V3 = Perception on extra volume of material to learn in comparison with traditional classes

$\mathrm{V} 5=$ Perception on extra volume of time to do assignments in comparison to traditional classes

V6 $=$ Perception on missing face-to-face-communication with instructor and classmates

The probability that a student will take a future online class is $p=1 /\left(1+e^{-Z}\right)$ (Norusis, 1990), where $\mathrm{Z}$ is calculated from Equation 1 above.

This analysis indicates that the most important variable negatively affecting the student's decision is the perception on missing face-to-face communication with the instructor and classmates (V6). The next two negative effects come from perceptions of having extra volume of materials to learn (V3) and extra time to do assignments in comparison to traditional classes (V5).

Given these negative perceptions of online classes, one could improve student acceptance by providing structured guidelines and schedules to assist them in handling the course materials in a timely manner. An instructor may promote and even participate regularly in online chat rooms to provide students a sense of belonging and to give them instant feedback.

\section{What Makes The Difference Between A Student's Decision Whether Or Not To Take A Future Online Class}

A Discriminant Analysis is conducted on performance indicators to understand what makes a difference between who will take a future online course (Group 1) and those who will not (Group 2). The weights of related variables are estimated so that they result in the best separation of the two groups. The following discriminant function is obtained from a stepwise process:

$\mathrm{D}=-3.526-.428 \mathrm{~V} 1+.409 \mathrm{~V} 3+.324 \mathrm{~V} 5+.570 \mathrm{~V} 6$

or in standardized coefficients (mean of 0 and standard deviation of 1):

$\mathrm{D}=-.443 \mathrm{~V} 1+.465 \mathrm{~V} 3+.355 \mathrm{~V} 5+.656 \mathrm{~V} 6$

On the magnitudes and signs of standardized coefficients, one notes that, once again, Variable V6 on the perception of missing face-to-face communication with the instructor and classmates has heavier weight and contributes the most in the discrimination between the two groups. Variable V1 on the perception of benefit of flexible class schedule with a negative sign emerges as a prominent contrast of these two groups. This discriminant function has a significant Chi-Square of $56.225(\mathrm{df}=4)$. 
In cross-validation, the jackknife, or leave-one-out method, is used to avoid splitting a relative small sample in this study into two smaller sets for estimation purposes (Norusis, 1990). Using this method, each case of the sample is left out in turn and the function is estimated with remaining $(n-1)$ cases. Then the estimated function will be used to classify the left-out case. Consequently, the case used for cross-validation is classified by the functions derived from all other cases. The classification matrix is reproduced in Table 3. This discriminant function classifies correctly $84.8 \%$ of the original grouped cases and $83.8 \%$ of the cross-validated grouped cases.

Table 3: Classification Matrix

\begin{tabular}{|c|c|c|c|c|}
\hline & & Predicted Group 1* & Predicted Group2** & Total \\
\hline \multirow[t]{2}{*}{ Original } & Actual Group 1* & $\begin{array}{c}40 \\
(81.6 \%)\end{array}$ & $\begin{array}{c}9 \\
(18.4 \%)\end{array}$ & $\begin{array}{c}49 \\
(100 \%)\end{array}$ \\
\hline & Actual Group2** & $\begin{array}{c}7 \\
(12.5 \%)\end{array}$ & $\begin{array}{c}49 \\
(87.5 \%)\end{array}$ & $\begin{array}{c}56 \\
(100 \%)\end{array}$ \\
\hline \multirow[t]{2}{*}{ Cross-Validated $* * *$} & Actual Group 1* & $\begin{array}{c}40 \\
(81.6 \%)\end{array}$ & $\begin{array}{c}9 \\
(18.4 \%)\end{array}$ & $\begin{array}{c}49 \\
(100 \%)\end{array}$ \\
\hline & Actual Group2** & $\begin{array}{c}8 \\
(14.3 \%)\end{array}$ & $\begin{array}{c}48 \\
(85.7 \%)\end{array}$ & $\begin{array}{c}56 \\
(100 \%)\end{array}$ \\
\hline
\end{tabular}

* Group 1: Students will take an online course again

** Group 2: Students will not take an online course again

*** Jackknife method is used for cross-validation

\section{An Exploratory Model Of Online Learning Acceptance}

A Factor Analysis is conducted to discover a comprehensive model of online learning acceptance based on measurements of directly observable variables/indicators related to student attitudes toward the learning process and outcome. From the Correlation Matrix of these indicators (Table 4), the Kaiser-Mayer-Oklin Measure of Sampling Adequacy of .743 indicates that the variables under study related together and are appropriate for factor analysis. The Barlett's Test of Sphericity, with significant Chi-Square of 472.45 ( $\mathrm{df}=78)$, confirms that the correlation matrix in the study contains sufficient variances for a significant analysis.

Table 4: Correlation Matrix of Indicators

\begin{tabular}{|c|c|c|c|c|c|c|c|c|c|c|c|c|c|c|}
\hline & V1 & V2 & V3 & V4 & V5 & V6 & V7 & V8 & V9 & V10 & V11 & V12 & V13 & V14 \\
\hline V1 & 1.000 & & & & & & & & & & & & & \\
\hline V2 & -.003 & 1.000 & & & & & & & & & & & & \\
\hline V3 & -.054 & .301 & 1.000 & & & & & & & & & & & \\
\hline V4 & -.234 & .359 & .438 & 1.000 & & & & & & & & & & \\
\hline V5 & -.152 & .238 & .222 & .626 & 1.000 & & & & & & & & & \\
\hline V6 & -.380 & .267 & -.005 & .318 & .188 & 1.000 & & & & & & & & \\
\hline V7 & -.335 & .133 & .094 & .145 & .170 & .586 & 1.000 & & & & & & & \\
\hline V8 & -.316 & .272 & .118 & .298 & .282 & .540 & .353 & 1.000 & & & & & & \\
\hline V9 & -.306 & .136 & .057 & .225 & .328 & .460 & .580 & .596 & 1.000 & & & & & \\
\hline V10 & .122 & -.053 & .019 & .010 & -.050 & -.065 & -.050 & -.061 & -.172 & 1.000 & & & & \\
\hline V11 & .044 & .107 & .084 & .128 & .187 & -.041 & .104 & .018 & .129 & .226 & 1.000 & & & \\
\hline V12 & .220 & .058 & -.192 & -.059 & -.027 & .097 & -.022 & .043 & -.022 & -.039 & .079 & 1.000 & & \\
\hline V13 & .555 & .036 & -.043 & -.070 & -.137 & -.364 & -.359 & -.285 & -.243 & .093 & .119 & .110 & 1.000 & \\
\hline V14 & .419 & -.023 & -.031 & -.061 & -.138 & -.325 & -.303 & -.243 & -.233 & .059 & .102 & .252 & .504 & 1.000 \\
\hline V15 & .562 & .045 & -.112 & -.154 & -.042 & -.414 & -.412 & -.277 & -.321 & .133 & .112 & .331 & .538 & .469 \\
\hline
\end{tabular}

Kaiser-Meyer-Olkin Measure of Sampling Adequacy : Bartlett's Test of Sphericity :

\begin{tabular}{ll} 
& .743 \\
Approx. Chi-Square & 472.450 \\
df & 78 \\
Sig. & .000 \\
\hline
\end{tabular}


Initial experiments reveal that V10 and V11 have low communalities and, in fact, have weak correlations with other indicators. Consequently, they are omitted from further analyses.

Two extraction methods;i.e., Principal Component (PC) and Maximum Likelihood (ML), are applied. Varimax rotation is used to ease the identification of underlying factors. In terms of percentage of residuals between observed and reproduced correlations, PC extraction results in 39 (or 50\%) non-redundant residuals with absolute values greater than .05 in comparison to 26 (or 33\%) such residuals from ML. Consequently, ML extraction is used in further studies since its capacity in reproducing correlation matrix is better.

Using the ML extraction method and Varimax rotation, the experiment arrives at the following factor patterns, explaining student acceptance of online learning. The model has a significant Chi-Square of $67.8(\mathrm{df}=42)$ with p-value of .007. Factor loadings and the exploratory model are reported in Table 5 and Figure 1.

- $\quad$ Factor 1 relates to Communication and Feedback with high loadings on indicators V6 on "face-to-face communication", V7 on "negative effect of face-to-face communication", V8 on "missing chance to ask instant question", and V9 on "negative effect of missing chance to ask instant question".

- Factor 2 relates to Course Outcome with high loadings on indicators V1 on "flexible class schedule", V12 on "instructor's leniency", V13 on "content/skills acquired", V14 on "grade received", and V15 on "sufficient prerequisites".

- $\quad$ Factor 3 relates to Effort Required with high loadings on indicators V2 on "extra effort", V3 on "extra material", V4 on "extra time to learn the material", and V5 on "extra time for assignments".

This exploratory model indicates that student acceptance of online instruction and Distance Learning is affected by the following three factors:

1. Students are concerned about the lack of face-to-face communication, especially missing of instant response/feedback and its negative effects on their learning.

2. Then they are anxious about what they might get from the class in terms of grades, content, and prerequisites with benefits of a flexible class schedule and the expected leniency from the instructor.

3. Last, students are worried about their extra time and effort for a perceived heavy load of course material.

To gain the online student acceptance, one should address these concerns in instructional design and the implementation process to alleviate their negative attitudes and provide them with successful outcomes and positive experiences.

Table 5: Factor Matrix - Factor Loadings

\begin{tabular}{|l|c|c|c|}
\hline & Factor 1 & Factor 2 & Factor 3 \\
\hline V1 & -.273 & $\mathbf{. 6 6 0}$ & .141 \\
\hline V2 & .253 & .141 & $\mathbf{. 3 4 2}$ \\
\hline V3 & & & $\mathbf{4 4 0}$ \\
\hline V4 & .136 & & $\mathbf{. 8 8 6}$ \\
\hline V5 & .231 & .600 \\
\hline V6 & $\mathbf{. 6 7 8}$ & -.260 & .206 \\
\hline V7 & $\mathbf{. 6 5 7}$ & -.279 & .200 \\
\hline V8 & $\mathbf{. 6 6 8}$ & -.123 & .116 \\
\hline V9 & $\mathbf{. 7 2 5}$ & -.134 & \\
\hline V12 & .164 & $\mathbf{. 4 1 2}$ & \\
\hline V13 & -.290 & $\mathbf{. 6 5 1}$ & \\
\hline V14 & -.248 & $\mathbf{. 5 7 4}$ & \\
\hline V15 & -.276 & $\mathbf{. 7 4 4}$ & \\
\hline
\end{tabular}

Notes:

Maximum Likelihood Extraction

Varimax Rotation with Kaiser Normalization

Factor Loadings < 100 Suppressed 


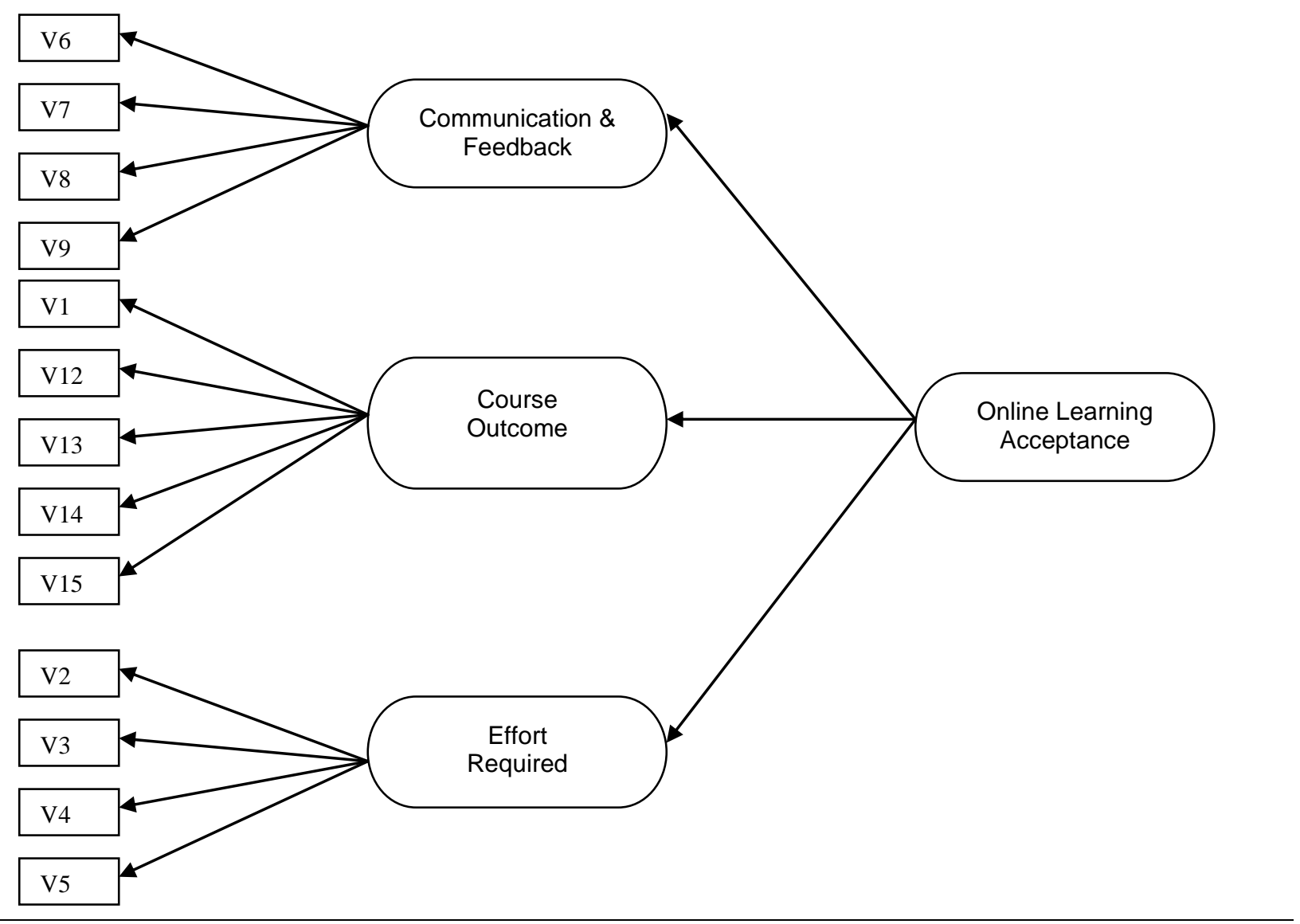

Figure 1: An Exploratory Model Of Online Learning Acceptance

\section{Field Observations From The Instructor}

This study has access to the notes of the instructor who offered this online course. The following are some field observations from an instructor's perspective.

This online class had a higher drop-out rate. Initially, 152 students registered for the course, but 40 students (or $26 \%$ ) dropped during various periods of the semester. In the same regular classes, one had only two to three dropouts (or $9 \%$ ) from 33 to 35 registered students.

Online students expected a greater level of leniency from the instructor in terms of deadlines for class work. A larger number of students asked for an extension than those in regular classes. Also, online students seem to feel insecure as they want reassurance from the instructor, such as asking for much more guidance on class projects, than students in traditional classes.

Many students seem not to be self-regulated as they did not visit the class web/bulletin board as regularly as advised/required by the instructor. Later, they were overwhelmed with the volume of class material and information accumulated over a week or even a longer period of time.

From data collected in the fifth week, students indicated that they spent about 2.19 hours per week, on average, to study for this 3-unit course - less than one studying-hour per online course unit. At the end of the course, students reported of spending an average of 13.25 hours per week on studying other 12 class units than this online course in the current semester - more than one studying-hour per traditional course unit. Students also perceived that 
they spent more time studying for this online course in order to cope with a perceived heavier class workload. This discrepancy - spending less time to study than they should have and ending in struggling more to survive the course - raises the issue of fostering students' study habits as well as self-motivation and self-discipline in future implementation of online courses.

Students expected that the online course would be an easier one. The average expected grade points for the course expressed by the students is 86 percent, whereas the actual class average, before curving and bonus, was only about 67 percent. In the end, online students performed lower in all exams. For three exams, the average grades were 62,66 , and 61 percent compared to 69,73 , and 71 percent in regular classes.

\section{CONCLUDING REMARKS}

This study offers some insights toward an effective instructional design for online instruction and Distance Learning in order to gain student acceptance. It has provided profiles and attitudes of a sample of online students enrolled in an introductory class of Information Systems offered to all business students. Preferences and perceptions expressed by respondents in this study are more than indifferent. Findings of this study confirm the merit of flexible schedule and the negative effect of a non face-to-face setting in an online class. Sample data show that, although the majority of adults and full-time students took this online course by their own preference, they still expressed their concerns on the lack of face-to-face communication. Students also perceived having heavier workloads but felt that they did not acquire more knowledge from this online class than from a traditional class. Overall, students tended to agree that they had learned sufficient prerequisite knowledge from this online class in order to follow other courses in their curricula.

This study provides a Logistic Regression equation to predict what makes students take future online courses. A Discriminant Analysis is offered to understand the differences in performance indicators between those who will take a future online course and those who will not. The study also proposes an exploratory model of online learning acceptance having three factors; namely, Communication/Feedback, Course Outcome, and Effort Required.

Analyses of findings reveal that the most important indicator negatively affecting student acceptance is their perception on missing face-to-face-communication with the instructor and classmates. The next two negative effects come from a perception on extra volume of materials to learn and extra time spent on assignments in comparison to traditional classes. The perception on benefit of flexible class schedule emerges as the prominent contrast of these two groups. Distance Learning seems to still be an unfamiliar learning environment. Overall, this study determines that students who have had a satisfactory outcome tend to take a similar online course in the future. This indicates that the preference for and acceptance of online courses build up with positive experience on recent courses taken.

From this study, apparently many students choose online courses out of their constraint of schedules rather than their preference for the unique delivery methods or the class settings of an online course. More research is warranted to identify factors that would enhance online courses so they could become alternatives of equal value to students rather than merely an option when schedules do not allow for a traditional course. Reasons for the high drop-out rate in online classes should be investigated in future studies with a survey of this particular student group. Further inquiries are also necessary to discover preferences across multiple online courses to make the model robust (Hiltz \& Arbaugh, 2003; and Arbaugh et al., 2009). Understanding what makes students accept online courses would be beneficial in effective instructional design to provide them with positive experiences and successful outcomes in Distance Learning.

\section{AUTHOR INFORMATION}

Dr. Dat-Dao Nguyen is a Professor of Information Systems in Department of Accounting and Information Systems at California State University - Northridge. He holds a PhD degree in MIS from Concordia University (Montreal, Canada). His researches have been published in IEBM Handbook of Information Technology in Business, The International Encyclopedia of Business and Management, The Internet Encyclopedia, Journal of Information Science and Technology, and Proceedings of Decision Sciences Institute, among others. E-mail: datdao.nguyen@csun.edu 
Dr. Yue "Jeff" Zhang is a Professor of Information Systems in Department of Accounting and Information Systems at California State University - Northridge. He holds a PhD degree in MIS from Oklahoma State University. His researches have been published in Encyclopedia of Information Science and Technology, Journal of International Technology and Information Management, International Journal of Services and Standards, Journal of Electronic Commerce Research, and Proceedings of Decision Sciences Institute, among others. E-mail: jeff.zhang@csun.edu

\section{REFERENCES}

1. Allen I.E. \& Seaman J. (2006). Making the Grade: Online Education in the United States. Retrieved from http://www.sloan-c.org/publications/survey/pdf/Making the Grade.pdf

2. Arbaugh J.B. (2000). An Exploratory Study of the Effects of Gender on Student Learning and Class Participation in an Internet-based MBA Course. Management Learning, 31, 533-549.

3. Arbaugh J.B., Godfrey M.R., Johnson M., Pollack B.L., Niedndoft, B., \& Wresch W. (2009). Research in Online and Blended Learning in the Business Disciplines: Key Findings and Possible Future Directions. Internet and Higher Education, 12, 71-87.

4. Asleitner H. \& Steinberg R. (2005). Are There Gender Differences in Web-based Learning? An Intergrated Model and Related Effect Sizes. AACE Journal, 13(1), 47-63.

5. $\quad$ Eom S.B., Wen H.J. \& Ashill N. (2006). Determinants of Students' Perceived Learning Outcomes and Satisfaction in University Online Education: An Empirical Investigation. Decision Sciences Journal of Innovative Education, 4(2), 215-235.

6. Gagne R. (1985). The Conditions of Learning and Theory of Instruction $\left(4^{\text {th }}\right.$ Ed.) New York: Holt, Rinehart and Winston.

7. Gagne R. \& Briggs L. (1974). Principles of Instructional Design. New York NY: Holt, Rinehart, and Winston.

8. Harrington R. \& Loffredo D.A. (2010). MBI Personality Type and Other Factors that Relate to Preference for Online versus Face-to-face Instruction. Internet and Higher Education, 13, 89-95.

9. Hiltz S.R. (1994). The Virtual Classroom: Learning without Limits via Computer Networks, Nordwood, NJ:Ablex Pub. Corp.

10. Hiltz S.R. \& Arbaugh J.H. (2003). Improving Quantitative Research Methods in Studies of Asynchronous Learning Networks. In J. Bourne and J.C. Moore (eds.) Elements of Quality Online Education: Practice and Direction, V.4 Sloan-C Series. Needham, MA: Sloan-Center for Online Education.

11. Hiltz S.R. \& Wellman B. (1997). Asynchronous Learning Networks as a Virtual Classroom: Communication of the ACM, 40(9), 44-49.

12. Holsapple C.W. \& Lee-Post A. (2006). Defining, Assessing, and Promoting E-Learning Success: An Information Systems Perspective. Decision Sciences Journal of Innovative Education, 4(1), 67-85.

13. Hornik S., Sanders C.S., Li Y., Moskal P.D., \& Dziuban C.D. (2008). The Impact of Paradigm Development and Course Level on Performance in Technology-mediated Learning Environments. Informing Sciences, 11, 35-57.

14. Janicki T. \& Steinberg G. (2003). Evaluation of a Computer-Supported Learning System. Decision Sciences Journal of Innovative Education, 1(2), 203-224.

15. Karacapilidis N. (Ed.) (2010). Novel Developments in Web-based Learning Technologies: Tools for Modern Teaching. Hershey, PA: IGI Global.

16. Koch J.V. (1998). How Women Actually Perform in Distance Education. The Chronicle of Higher Education, September 11, 1998, p. A60.

17. Leidner D. \& Jarvenpaa S. (1995). The Use of Information Technology to Enhance Management School Education: A Theoretical View. MIS Quarterly, 19(3), 65-291.

18. Lengnick-Hall C.A \& Sanders M.M. (1997). Designing Effective Learning Systems for Management Education: Student Roles, Requisite Variety, and Practicing What We Teach. Academy of Management Journal, 40(6), 1334-1368.

19. Lu J., Yu C., \& Liu C. (2003). Learning Style, Learning Patterns, and Learning Performance in a WebCTbased MIS Course. Information \& Management, 40(6), 497-507.

20. Marks R.B., Sibley S.D. \& Arbaugh J.B. (2005). A Structural Equation Model of Predictors for Effective Online Learning. Journal of Management Education, 29(4), 531-563. 
21. Melone, N. (1990). A Theoretical Assessment of the User-satisfaction Construct in Information Systems Research. Management Science, 36(1), 76-91.

22. Merrill M.D. (1994). Instructional Design Theory. Englewood Cliffs, NJ: Educational Technology Publications.

23. Moore J.C (2005). The Sloan Consortium Quality Framework and The Five Pillars. Retrieved March 2007 from http://www.sloan-c.org/publications/books/qualityframework.pdf

24. Norusis M.J. (1990). SPSS Advanced Statistics User's Guide. Chicago, IL: SPSS Inc.

25. Piccoli G., Ahmad R. \& Ives B. (2001). Web-base Virtual Learning Environments: A Research Framework and a Preliminary Assessment of Effectiveness in Basic IT Skills Training. MIS Quarterly, 25(4), 401-426.

26. Ritzhaupt A.D., Stewart M., Smith P. \& Barron A.E. (2010). An Investigation of Distance Education in North American Research Literature Using Co-word Analysis. International Review of Research in Open and Distance Learning, 11(1), 38-60.

27. Rungtusanatham M., Ellram L., Siferd S.P. \& Salik S. (2004). Toward a Typology of Business Education in the Internet Age. Decision Sciences Journal of Innovative Education, 2(2), 101-120.

28. Schniederjans M.J. \& Kim E.B. (2005). Relationship of Student Undergraduate Achievement and Personality Characteristics in a Total Web-based Environment: An Empirical Study. Decision Sciences Journal of Innovative Education, 3(2), 205-221.

29. Schrag F. (1992). Conceptions of Knowledge. In P. Jackson (ed.) Handbook of Research on Curriculum. New York, NY: MacMillan, New York.

30. Wan Z., Wang Y. \& Haggerty N. (2008). Why People Benefit from e-Learning Differently: The Effects of Psychological Processes on e-Learning outcomes. Information \& Management. 45, 513-521.

31. Wang Y. (2003). Assessment of Learner Satisfaction with Asynchronous Electronic Learning Systems. Information \& Management. 41, 75-86.

32. Worthen B.R \& Sanders J.R. (1987). Educational Evaluation: Alternative Approaches and Practical Guidelines. White Plains, NY: Longman.

33. Yan Z. (2004). The Psychology of e-learning: Why, What and How? In J. Bourne \& J.C. Moore (eds.) Elements of Quality Online Education: Into the Mainstream, V.5 Sloan-C Series, Needham, MA: SloanCenter for Online Education.

34. Zawacki-Richter O, Backer E.M. \& Vogt S. (2009). Review of Distance Education Research (2000 to 2008): Analysis of Research Areas, Methods, and Authorship Patterns. International Review of Research in Open and Distance Learning, 10(6), 21-50. 


\section{NOTES}

